\title{
Past trends in obesity-attributable mortality in eight European countries: an application of age-period-cohort analysis
}

\author{
Nikoletta Vidra ${ }^{1} \cdot$ Maarten J. Bijlsma ${ }^{2} \cdot$ Sergi Trias-Llimós ${ }^{1} \cdot$ Fanny Janssen ${ }^{1,3}$
}

Received: 30 November 2017/Revised: 23 May 2018/Accepted: 24 May 2018/Published online: 4 June 2018

(C) The Author(s) 2018

\begin{abstract}
Objectives To assess age, period, and birth cohort effects and patterns of obesity-attributable mortality in Czech Republic, Finland, France, Germany, Hungary, Italy, Poland, and the UK (UK).

Methods We obtained obesity prevalence and all-cause mortality data by age (20-79), sex and country for 1990-2012. We applied Clayton and Schifflers' age-period-cohort approach to obesity-attributable mortality rates (OAMRs).

Results Between 1990 and 2012, obesity prevalence increased and age-standardised OAMRs declined, although not uniformly. The nonlinear birth cohort effects contributed significantly $(p<0.01)$ to obesity-attributable mortality trends in all populations, except in Czech Republic, Finland, and among German women, and Polish men. Their contribution was greater than 25\% in UK and among French women, and larger than that of the nonlinear period effects. In the UK, mortality rate ratios (MRRs) increased among the cohorts born after 1950. In other populations with significant birth cohort effects, MRRs increased among the 1935-1960 cohorts and decreased thereafter.

Conclusions Given its potential effects on obesity-attributable mortality, the cohort dimension should not be ignored and calls for interventions early in life next to actions targeting broader societal changes.
\end{abstract}

Keywords Obesity $\cdot$ Mortality $\cdot$ Birth cohort $\cdot$ APC analysis $\cdot$ Europe

\section{Introduction}

Obesity has increased dramatically in recent decades and is now considered a global epidemic (Finucane et al. 2011). While the United States (USA) still has the highest obesity prevalence (OECD 2014) (36.5\% in 2011-2014), Europe ranks second (Eurostat 2017), with national prevalence levels ranging from 10 to $30 \%$ (Eurostat 2017). Obesity has

Electronic supplementary material The online version of this article (https://doi.org/10.1007/s00038-018-1126-2) contains supplementary material, which is available to authorized users.

Nikoletta Vidra

n.vidra@rug.nl

1 Population Research Centre, Faculty of Spatial Sciences, University of Groningen, PO Box 800, 9700 AV Groningen, The Netherlands

2 Max Planck Institute for Demographic Research, Rostock, Germany

3 Netherlands Interdisciplinary Demographic Institute, The Hague, The Netherlands major consequences for individual and for population health, as it increases the risk of a range of diseases (Field et al. 2001) and consequently the risk of dying (Global BMI Mortality Collaboration 2016). In order to set effective health policy priorities, it is essential to study the obesity epidemic and gain an understanding of how it evolved over time (Finucane et al. 2011).

Previous studies that examined time trends in obesity prevalence have provided valuable insight into how the epidemic evolved, the differences that exist across countries and between men and women, and the underlying factors (Finucane et al. 2011). Previous studies that focused on estimating the health burden of obesity by assessing obesity-attributable mortality were mostly conducted in the USA (Allison et al. 1999; Flegal et al. 2005; Mehta and Chang 2009) and to a lesser extent in Europe (Banegas et al. 2003; Kelly et al. 2009) and did not assess trends over time. To the best of our knowledge, only one previous study has examined the long-term trends in the share of mortality due to obesity in Canada indicating that this share increased over time (Katzmarzyk and Ardern 2004). 
Few of the aforementioned studies took into account the multiple dimensions of the obesity epidemic: namely, age, period, and birth cohort (Reither et al. 2009). It is well known that age affects obesity, as declining levels of physical activity and physiological changes occur with increasing age (Reither et al. 2009). In addition, broad societal changes, such as the increase of sedentary lifestyles and the consumption of high-calorie foods, have contributed to increases in obesity over calendar time (period effects) (Masters et al. 2013; Reither et al. 2011). However, differences in the obesity prevalence levels among people born in different years (i.e., (birth) cohort effects) exist as well (Reither et al. 2011).

Birth cohort membership is important because it could indicate the degree to which individuals are receptive to societal and social changes (Hellevik 2002; Reither et al. 2009). Compared to older birth cohorts, younger birth cohorts are more likely to have a high-calorie diet and a sedentary lifestyle, largely because they are more receptive to using modern technologies, products, and media (Reither et al. 2009). Birth cohort effects may also reflect longlasting effects of exposures earlier in life (Janssen and Kunst 2005). A growing body of evidence indeed shows that excess fat in adolescence or early adulthood and weight gain over the life course have long-term implications for metabolic, cardiovascular, and mortality risk (Yu 2012). Because of these long-lasting effects, birth cohort dynamics are key to understanding the future of health and longevity (Masters et al. 2013).

The few previous studies that have applied age-periodcohort (APC) analyses to obesity prevalence found that age, period, and cohort effects were all important (Diouf et al. 2010; Jiang et al. 2013; Masters et al. 2013). While there are no APC analyses of obesity-attributable mortality, $\mathrm{Yu}$ applied APC analysis to mortality differentials associated with body mass ( $Y u$ 2012), and Masters estimated obesity-attributable mortality by birth cohort and found more deaths among younger than older birth cohorts (Masters et al. 2013). However, neither study focused on Europe.

Our study is the first to assess age, period, and birth cohort effects and patterns in past obesity-attributable mortality trends in Europe.

\section{Methods}

\section{Design}

We estimated obesity-attributable mortality trends from 1990 to 2012 for the adult populations of eight European countries: the Czech Republic, Germany, Finland, France, Hungary, Italy, Poland, and the UK.
To warrant the data quality, we included only European countries for which the trends in obesity prevalence, which we obtained from the Global Burden of Disease (GBD) study ( $\mathrm{Ng}$ et al. 2014), revealed similar patterns as those based on data from the Organisation for Economic Cooperation and Development (OECD 2016). Also, we ensured that the included countries comprise the four different European regions and differ in terms of the levels, patterns, and trends in obesity prevalence. To ensure that the obesity prevalence data and the all-cause mortality data were closely aligned, we restricted our analysis to the period 1990-2012. We focused on the adult population aged 20-79, because the prevalence data had $80+$ as the final open-ended age category with unknown upper. The combination of ages 20-79 and calendar years 1990-2012 resulted in the inclusion of the birth cohorts from 1911 to $1992($ cohort $=$ period - age $)$.

\section{Data}

Estimated obesity prevalence data (BMI $\geq 30 \mathrm{~kg} / \mathrm{m}^{2}$ ) (WHO 1998) were obtained from the GBD study by country, five-year age groups, sex, and single calendar year for the period 1990-2012 ( $\mathrm{Ng}$ et al. 2014). These data were generated by using a spatiotemporal regression and a Gaussian process regression, which allow dealing with the available prevalence data from different sources and missing data ( $\mathrm{Ng}$ et al. 2014).

We obtained all-cause death numbers and exposure population numbers by country, sex, five-year age groups, and year from the Human Mortality Database (2016).

\section{Analysis}

We performed all of our analyses separately for men and women.

\section{Obesity-attributable mortality}

To calculate the obesity-attributable mortality fractions by country, year, age and sex, that we shall refer to as obesityattributable mortality fraction (OAMF), we used the Rockhill formula for the population-attributable fraction (PAF) (Rockhill et al. 1998):

$\mathrm{OAMF}_{a, s}=\frac{P_{a, s} \cdot(\mathrm{RR}-1)}{1+P_{a, s} \cdot(\mathrm{RR}-1)}$

where $P_{a, s}$ is the obesity prevalence in five-year age group $a$ and sex $s$ by country and year and RR the relative risk of mortality associated with obesity (Rockhill et al. 1998). We used the RR from a recent meta-analysis based on European studies that adjusted for at least age, sex, and smoking (Flegal et al. 2013). In using an adjusted RR in the Rockhill 
formula, we basically applied the "partially adjusted method" for estimating PAFs (Flegal et al. 2004). Because the sex differences in the RRs were only marginal, we used the overall RR of 1.27 (Flegal et al. 2013).

Age- and sex-specific obesity-attributable mortality deaths were estimated by multiplying age- and sex-specific OAMF by the corresponding deaths. All-age obesity-attributable mortality fractions were obtained by dividing the sum of age-specific obesity-attributable mortality deaths by the total deaths for each sex.

The obesity-attributable mortality rates (OAMRs) were obtained by dividing the age- and sex-specific obesity-attributable deaths by the corresponding exposure populations. These five-year age group obesityattributable mortality rates were subsequently turned into single age-specific mortality rates by applying two-dimensional P-splines smoothing (Camarda 2012).

\section{Descriptive analysis}

The age-specific obesity-attributable mortality rates by birth cohort were depicted in graphs, where we have selected single ages 5 years apart, to improve the visual clarity. The obesity-attributable mortality rates and obesity prevalence levels were directly age-standardised to ensure their comparability across countries, thereby using the sexspecific European population of 2011 as a standard (Eurostat 2016).

\section{Age-period-cohort (APC) modelling}

We applied age-period-cohort (APC) modelling to obesity-attributable mortality rates. The section below follows largely the APC methodology, as described by Bijlsma et al. (2012).

In modelling the obesity-attributable mortality rates as a function of age, period, and birth cohort, the linear dependency between the three variables $(a=p-\mathrm{c})$ needs to be taken into account to avoid over-identification. We therefore applied the standard Clayton and Schifflers approach (Clayton and Schifflers 1987a, b). This method, which has been used in previous demographic (Janssen and Kunst 2005) and epidemiological studies (Bijlsma et al. 2012; Dhillon et al. 2011), distinguishes between age effects, the effect of the shared linearity of period and birth cohort (referred to as drift), the nonlinear period effects, and the nonlinear birth cohort effects.

We applied four Poisson regression models to obesityattributable death numbers for each county and sex combination, setting the natural logarithm of the exposure population as an offset term. The age (A) model is defined by: $\ln \left[m_{a}\right]=\mu+\alpha_{a}$; the age-drift (AD) model is defined by $\ln \left[m_{a d}\right]=\mu+\alpha_{a}+\delta$; the age-period (AP) model is defined by $\ln \left[m_{a p}\right]=\mu+\alpha_{a}+\beta_{p}$; and the age-periodcohort (APC) model is defined by $\ln \left[m_{a p c}\right]=\mu+\alpha_{a}+\beta_{p}+\gamma_{c}$. Here, $m$ is the obesity-attributable mortality rate, $\mu$ is the intercept, $\alpha, \beta$, and $\gamma$ represent the age, period, and birth cohort effects, and $\delta$ represents the drift (Janssen and Kunst 2005).

We used as constraints two categories of birth cohorts, as this approach allowed us to estimate and visualise the nonlinear birth cohort effects separately from the linear time trend changes. As reference categories, we used age 50, calendar year 2000, and the 1935 and 1970 birth cohorts. Age 50 and calendar year 2000 represent the middle observations of our data (1990-2012; 20-79). The two reference categories for the cohort dimension were chosen so that they do not refer to the extreme birth cohorts with fewer observations, but still lie as much apart as possible so as to separate a long-term linear trend from the nonlinear deviations of that trend (Bijlsma et al. 2012; Trias-Llimos et al. 2017). For comparative purposes, we used the same reference categories for all countries and both sexes in our analysis.

To determine the statistical contribution of birth cohort to observed trends and levels, we compared the goodness of fit of age (A), age-drift (AD), age-period (AP), and ageperiod-cohort (APC) for the different models. Using the deviance statistic, a measure of goodness of fit, we performed both likelihood ratio tests of the $\mathrm{A}, \mathrm{AD}, \mathrm{AP}$, and APC models to the data, and likelihood ratio tests for model reduction. Due to our interest in birth cohorts, the primary comparison for the model reduction tests was APC with $\mathrm{AP}$, but we also compared $\mathrm{AD}$ with $\mathrm{A}$ and $\mathrm{AP}$ with $\mathrm{AD}$. Reduction in deviance is expressed as percentage reduction in deviance between the age-only model and the APC model. In our graphs, we show the cohorts born between 1920 and 1980, as observations for more extreme cohorts were less complete. All of the data analyses were performed using R 3.2.5 in R studio 0.99.451.

\section{Results}

Over the calendar years 1990-2012, age-standardised obesity prevalence increased among the adult populations in all eight countries, albeit not to the same extent (Fig. 1). The biggest increases were in the UK, followed by Finland and Germany. In the Czech Republic, France, Poland, Italy, Hungary, and Germany (women only), rising obesity periods were accompanied by periods in which a levelling off occurred. Age-standardised obesity prevalence was generally higher among women than men. In 2012, obesity prevalence was highest in the UK (26\%) and was lowest 


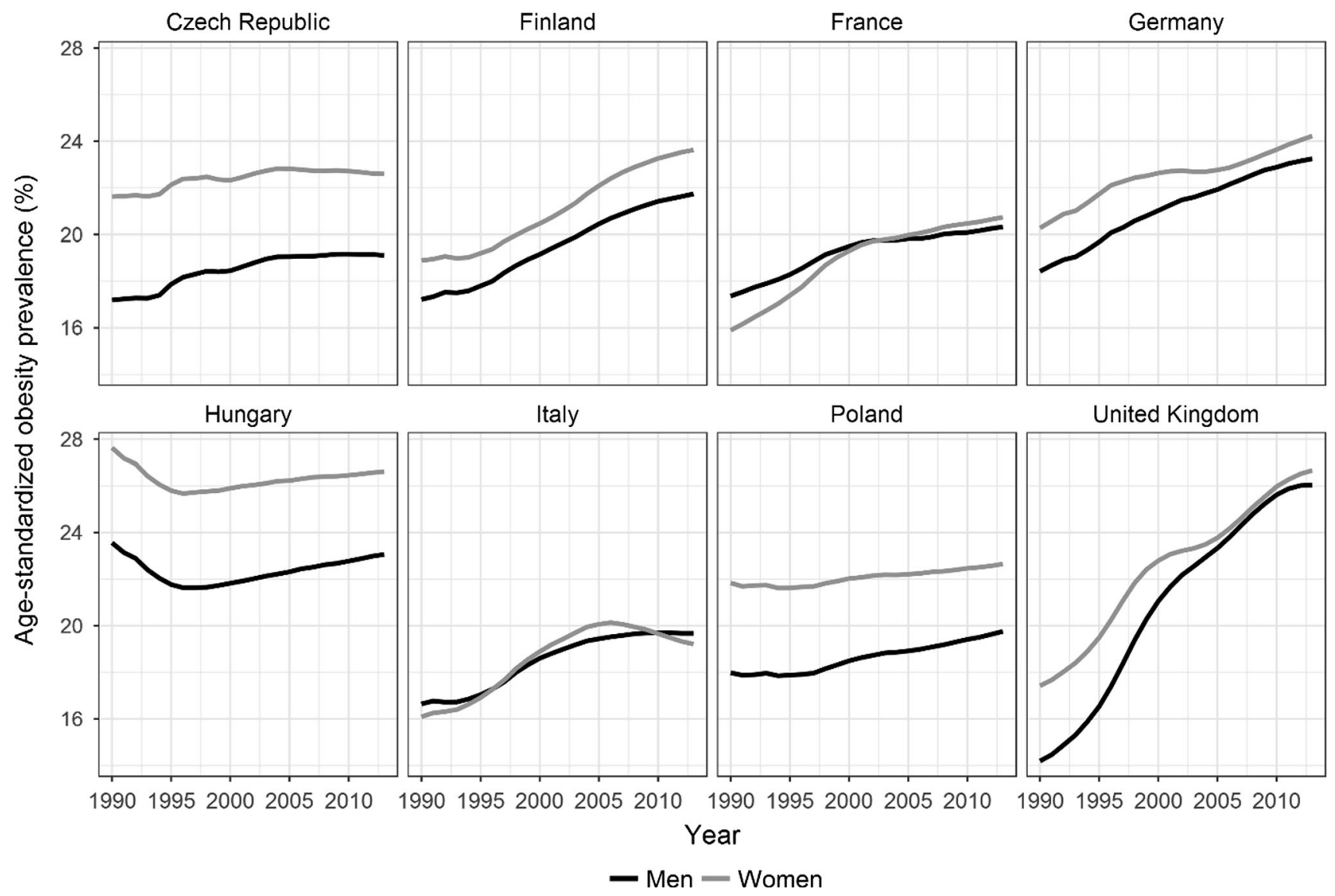

Fig. 1 Age-standardised obesity prevalence trends by sex in populations aged 20-79 years in eight European countries, 1990-2012

(less than 20\%) in Italy and among men in the Czech Republic and Poland.

The trends in the sex-specific obesity-attributable mortality fraction (OAMF) look similar to the trends in agestandardised obesity prevalence except for Hungarian and Polish women (see Online resource Fig. S1). In 2012, the share of all-cause mortality due to obesity ranged from $5.43 \%$ (France) to $7.07 \%$ (UK) among men, and from $4.85 \%$ (France) to $8.21 \%$ (Germany) among women. Between 1990 and 2012, the OAMF increased in all of the countries except in Hungary and among Polish women, albeit not to the same extent.

Over time, the age-standardised obesity-attributable mortality rates (OAMRs) declined in all of the populations studied, although not uniformly (Fig. 2). The pace of the decline was relatively fast in Hungary, the Czech Republic, and Poland, but was relatively moderate throughout the period in Finland, Germany, and Italy. Among French women and British men and women, the OAMRs increased prior to 2000. Over the same period, the age-standardised all-cause mortality rates decreased faster than the age-standardised OAMRs (see Online resource Fig. S2).
For the majority of the countries, the age-specific obesity-attributable mortality rates showed an overall decline across birth cohorts. However, for the UK especially we observed increasing obesity-attributable mortality rates across younger birth cohorts (Fig. 3).

Our modelling of the obesity-attributable mortality trends showed that, in addition to the age effects, both the nonlinear period effects and the nonlinear cohort effects proved to be significant (see Table 1). The contribution of the nonlinear birth cohort effects to the obesity-attributable mortality trends was statistically significant ( $p$ values $<0.01$ ) among French, Hungarian, Italian, and British men and women and among German men and Polish women (Table 1). For all sex-specific populations, the APC models provided a good fit to the data ( $p$ values > 0.999) (see Online Resource Table S1).

The contribution of the nonlinear birth cohort effect to the model fit ranged from $1.60 \%$ (Czech Republic) to $57.9 \%$ (UK) in men and in women from $0.25 \%$ (Czech Republic) to $28 \%$ (France). The largest contribution of the nonlinear birth cohort effects was among British men (57.9\%), while the nonlinear birth cohort contributed more than $25 \%$ to the deviance reduction among French and British women. In all of the countries and among both men 


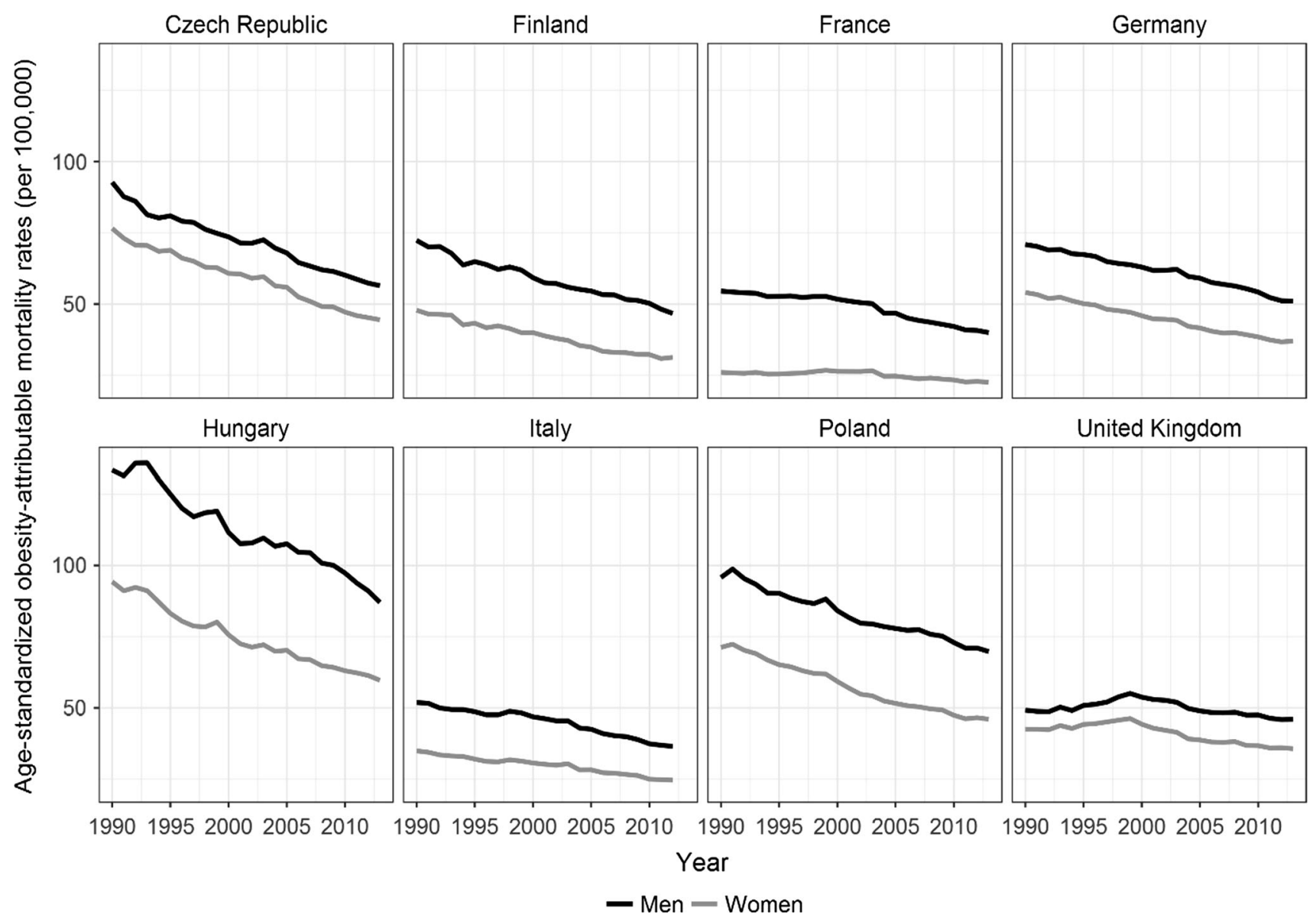

Fig. 2 Age-standardised obesity-attributable mortality rates (OAMRs) by sex in populations aged 20-79 years in eight European countries, 1990-2012

and women, the contribution of the nonlinear birth cohort effects was larger than the contribution of the nonlinear period effects. The drift made the largest contribution to the deviance reduction, exceeding $75 \%$ in all countries and among both men and women, except in the UK and among French women (Fig. 4).

In the UK, obesity-attributable mortality rate ratios started to increase among the cohorts born after 1950 (Fig. 5). This trend was followed by a slight decline among British men born after 1975 . In the remaining populations with significant cohort effects (German men; Polish women; and French, Hungarian, and Italian men and women), mortality rate ratios increased among the cohorts born between 1935 and 1960 and decreased among the cohorts born after 1960 .

\section{Discussion}

\section{Summary of results}

Between 1990 and 2012, obesity prevalence increased and OAMRs declined in the eight European countries studied, albeit with notable differences across countries, between men and women, and over time. Throughout, the APC models provided a good data fit $(p>0.999)$. Nonlinear birth cohort effects contributed significantly $(p<0.01)$ to the obesity-attributable mortality trends in all of the countries studied, except in the Czech Republic, Finland, Germany (women), and Poland (men). The contribution of these effects was greater than $25 \%$ in the UK and among French women, and was larger than the nonlinear period effects. However, drift, the linear component of the period and the cohort, was the largest contributor, except among British men. In general, obesity-attributable mortality rate ratios decreased among the subsequent birth cohorts, except among the cohorts born after 1950 in the UK and among the cohorts of German men; Polish women; and 


\section{Men}

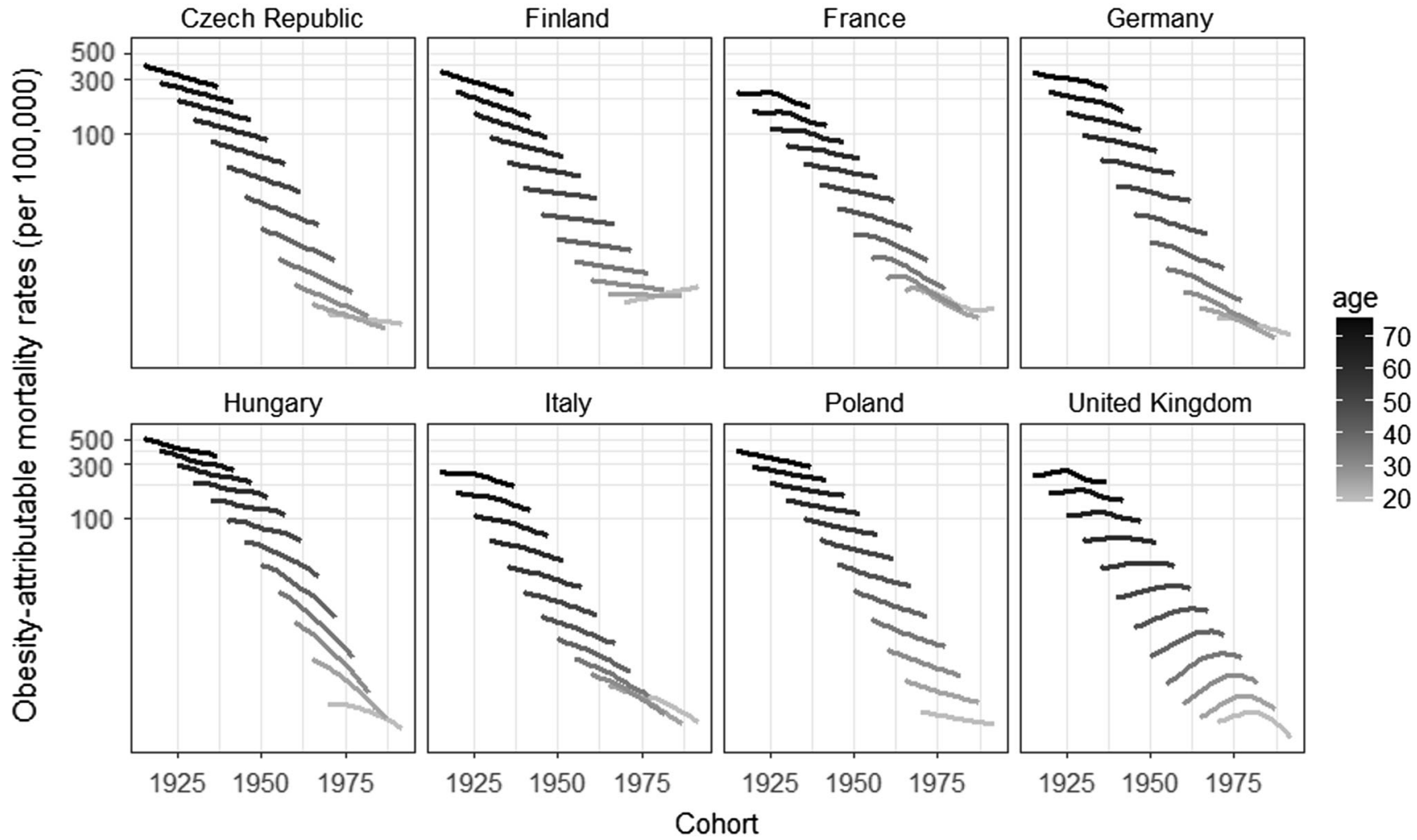

Women
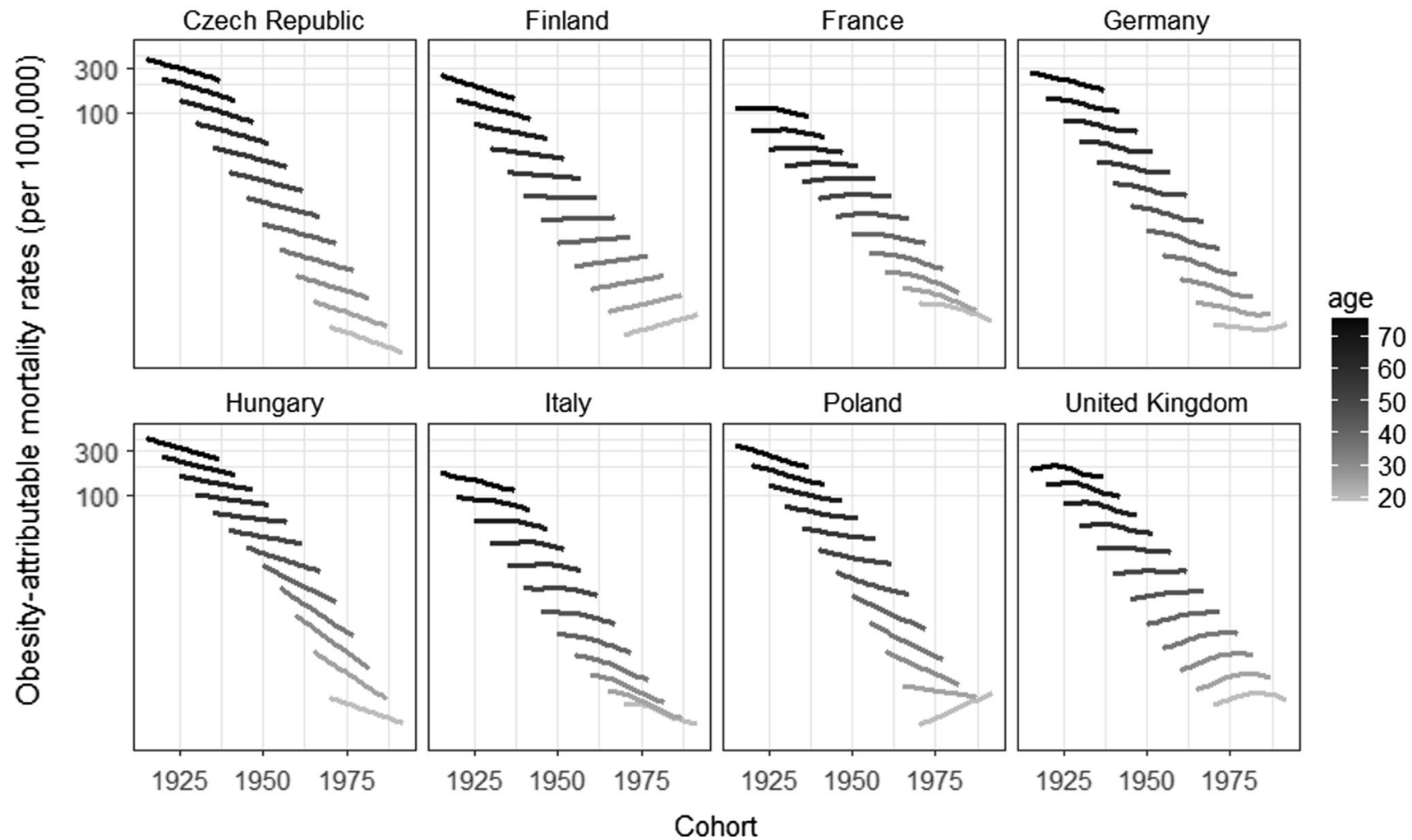

Fig. 3 Age-specific obesity-attributable mortality rates (OAMRs) by birth cohort (1911-1992) (log scale) and sex, in populations aged 20-79 years in eight European countries, 1990-2012 
Table 1 Model reduction (log-likelihood ratio) test of the age-drift, age-period, and age-period-cohort models by sex in populations aged 20-79 years in eight European countries, 1990-2012

\begin{tabular}{|c|c|c|c|c|c|c|c|c|}
\hline & Czech Republic & Finland & France & Germany & Hungary & Italy & Poland & UK \\
\hline \multicolumn{9}{|l|}{ Men } \\
\hline Age drift (AD) & $<0.001 * *$ & $<0.001 * *$ & $<0.001 * *$ & $<0.001 * *$ & $<0.001 * *$ & $<0.001 * *$ & $<0.001 * *$ & $<0.001 * *$ \\
\hline Age period (AP) & $>0.999$ & $>0.999$ & $<0.001 * *$ & $<0.001 * *$ & 0.096 & $<0.001 * *$ & $>0.999$ & $<0.001 * *$ \\
\hline Age period cohort (APC) & $>0.999$ & $>0.999$ & $<0.001 * *$ & $<0.001 * *$ & $<0.001 * *$ & $<0.001 * *$ & 0.665 & $<0.001 * *$ \\
\hline \multicolumn{9}{|l|}{ Women } \\
\hline Age drift (AD) & $<0.001 * *$ & $<0.001 * *$ & $<0.001 * *$ & $<0.001 * *$ & $<0.001 * *$ & $<0.001 * *$ & $<0.001 * *$ & $<0.001 * *$ \\
\hline Age period (AP) & $>0.999$ & $>0.999$ & $<0.001 * *$ & $<0.814$ & $>0.999$ & $<0.001 * *$ & 0.944 & $<0.001 * *$ \\
\hline Age period cohort (APC) & $>0.999$ & 0.923 & $<0.01 * *$ & 0.351 & $<0.01 * *$ & $<0.001 * *$ & $<0.001 * *$ & $<0.001 * *$ \\
\hline
\end{tabular}

Log-likelihood ratio test of model reductions in deviance comparing AD to A, AP to AD, and APC to AP

Statistical significance at $p$ value $<0.05, * * p$ value $<0.01$

Fig. 4 Contribution of the drift, the nonlinear period effect and the nonlinear cohort effect to the deviance reduction between the age model and the age-periodcohort model applied to obesityattributable mortality, by sex in populations aged $20-79$ years in eight European countries, 1990-2012

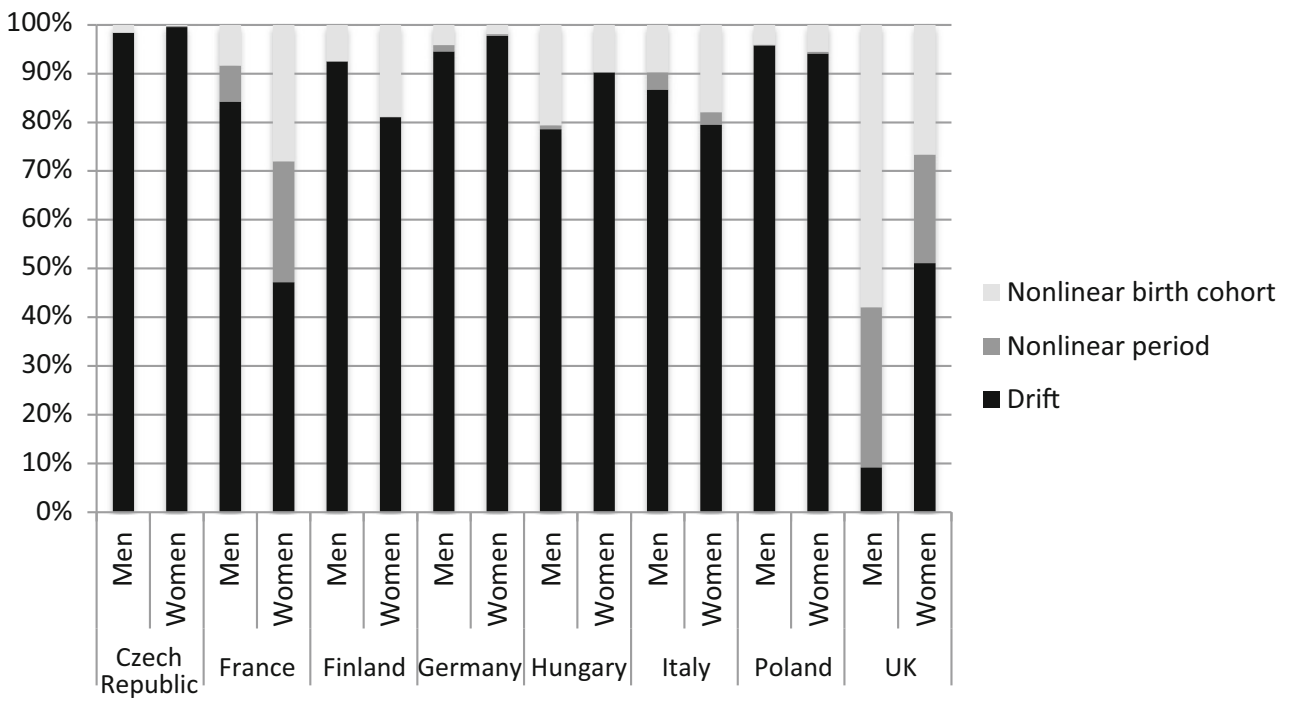

French, Hungarian, and Italian men and women born between 1935 and 1960 .

\section{Evaluation of data and methods}

In estimating the share of mortality due to obesity (OAMF), we were hampered by data limitations regarding prevalence and RRs. As obesity prevalence trends were different for different sources, we restricted our analysis to countries for which the obesity prevalence trends from the GBD (Ng et al. 2014) were similar to those by the OECD (OECD 2016). Secondly, and in line with previous studies, we applied adjusted RRs to the Rockhill formula, originally developed for the use of non-adjusted RRs (Flegal et al. 2004), as unadjusted RR were not readily available. Thirdly, the method we used was driven by the availability of data. Although other methods to estimate PAF could have affected the obesity-attributable mortality levels, they would not have affected the trends. Fourthly, because RRs of dying from obesity are not available by country and year, we applied one time-constant European-specific RR (Flegal et al. 2013). A sensitivity analysis where we applied the only available information on declines in RR from the USA (Mehta et al. 2014) revealed that this primarily affected drift and period trends and had no influence on the observed nonlinear cohort trends.

Smoking is importantly affecting overall mortality levels and trends (Thun et al. 2012) and could therefore bias our estimate of obesity-attributable mortality which we obtain by multiplying the obesity-attributable mortality fraction with all-cause mortality. A sensitivity analysis in which we applied our obesity-attributable mortality fractions to non-smoking-related mortality (Janssen et al. 2013) resulted, however, in almost identical cohort patterns. 


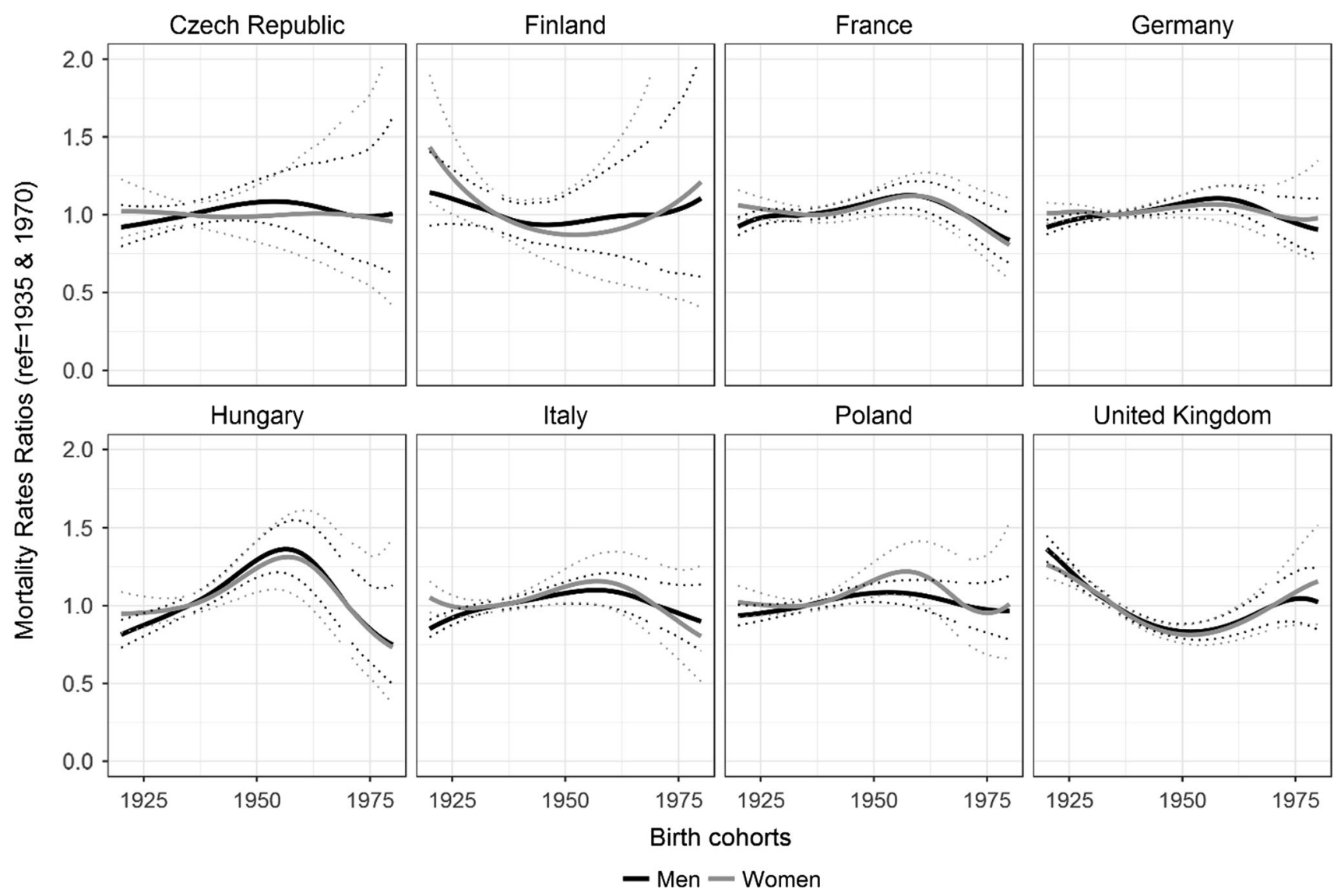

Fig. 5 Nonlinear birth cohort patterns by sex in populations aged 20-79 years in eight European countries, 1990-2012

To differentiate between the age, period, and cohort effects, we used the often-applied Clayton and Schifflers approach (Clayton and Schifflers 1987a, b). By separately modelling the shared linearity of the period and birth cohort effects (referred to as drift), this approach enabled us to estimate the nonlinear period effects and the nonlinear birth cohort effects. The resulting contributions are, however, underestimates of the complete period and cohort effects, which comprise both the nonlinear effects and the linear effects which are embedded in the drift. Especially when drift is large-as it is in our study - the underestimation can be substantial.

The choice of constraints within the APC analysis indeed has the potential to affect the patterns of age, period, and cohort, but not the relative importance of their nonlinear contributions (Fig. 4). A sensitivity analysis, in which we applied two alternative sets of cohort constraints (see Online resource Figs. S3, S4), revealed that our estimated cohort patterns proved in general robust, albeit less so for Hungary and Finland. Therefore, our results and main conclusion were not affected by the choice of constraints.

\section{Explanation of the results}

The decline in the age-standardised OAMRs that we observed might look counterintuitive at first, given the general increase we found in the age-standardised obesity prevalence and in the OAMFs. The more rapid decline of age-standardised all-cause mortality rates compared to the decline in obesity-attributable mortality rates indicates that while obesity indeed had an impact on mortality trends, the observed increase in the OAMFs could not compensate for the greater overall decline in the all-cause mortality rates. For the USA, similar declines in obesity-attributable mortality were observed (Flegal et al. 2005; Mehta and Chang 2009).

Our results show that the cohort dimension is important. Especially for the UK, we were able to demonstrate that nonlinear birth cohort effects made a large contribution to obesity-attributable mortality trends, especially among men (58\%) but also among women (27\%). The strong cohort effect for the UK can be linked to the finding that more recent UK birth cohorts developed greater probabilities of overweight or obesity at younger ages (Johnson et al. 2015). The observed cohort effect also seems to be another indicator of the further progression of the obesity epidemic 
in the UK compared to other European countries, next to the higher obesity levels and the sharper increase in obesity prevalence over time (Lifestyles Statistics Team 2014). The cohort patterns for the UK show that obesity-attributable mortality has been increasing among the cohorts born after 1950, which was also reflected in the agespecific obesity-attributable mortality rates by cohorts (Fig. 5).

A similar birth cohort pattern in obesity-attributable mortality rates was observed in the USA (Masters et al. 2013). The consistently lower overweight and obesity prevalence in the UK compared to the USA, combined with a more rapid recent increase (Public Health England 2016), illustrate that the UK is still in the upward dynamic of the obesity epidemic, but that the USA is further ahead. In both phases of the obesity epidemic the cohort dimension thus is important. The evidence showing that there are strong cohort effects and increasing trends in obesity among the younger birth cohorts in these countries points to the need of policy interventions focusing on early life conditions (Reither et al. 2009).

The cohort patterns for the populations among whom the cohort effects were significant-German men; Polish women; and French, Hungarian, and Italian men and women-reveal that the OAMRs increased among the cohorts born between 1935 and 1960, and decreased among the cohorts born after 1960. This cohort pattern is not in line with the increasing levels of receptivity in younger birth cohorts, brought by societal and social changes (Reither et al. 2009). A more likely explanation for the observed increase is that the cohorts born around the time of the Second World War experienced food restrictions even in utero. Poor gestational nutrition may have led to metabolic adaptations of the foetus, thereby increasing the propensity of these cohorts to become obese in adulthood, particularly in an obesogenic environment (Pico et al. 2012).

\section{Overall conclusion and implications}

Next to age and period effects on obesity-attributable mortality, we also observed cohort effects. The substantial birth cohort effect for the UK, with increases in obesity-attributable mortality for those born after 1950, indicates that the UK is following the trajectory of the USA in the obesity epidemic. Other European countries will likely follow the footsteps of the UK and the USA, unless action is being taken. The presence of a cohort effect, reflecting effects that happen early in the life course with long-lasting outcomes, calls for interventions early in life next to actions targeting societal changes which represent period effects.
The cohort dimension should not be ignored in future studies. It provides an important element in our understanding of complex public health problems such as obesity-attributable mortality. Moreover, it can facilitate targeted actions to birth cohorts at elevated risks and-in line with the ageing of current cohorts-inform future obesity-attributable mortality levels.

Acknowledgements This study is financed by the Netherlands Organisation for Scientific Research (NWO) as part of the research programme "Smoking, alcohol, and obesity, ingredients for improved and robust mortality projections", Grant Number 452-13-001. See https://www.futuremortality.com.

\section{Compliance with ethical standards}

Conflict of interest The authors declare that they have no conflict of interest.

Open Access This article is distributed under the terms of the Creative Commons Attribution 4.0 International License (http://creative commons.org/licenses/by/4.0/), which permits unrestricted use, distribution, and reproduction in any medium, provided you give appropriate credit to the original author(s) and the source, provide a link to the Creative Commons license, and indicate if changes were made.

\section{References}

Allison DB, Fontaine KR, Manson JE, Stevens J, VanItallie TB (1999) Annual deaths attributable to obesity in the United States. JAMA 282:1530-1538

Banegas JR, Lopez-Garcia E, Gutierrez-Fisac JL, Guallar-Castillon P, Rodriguez-Artalejo F (2003) A simple estimate of mortality attributable to excess weight in the European Union. Eur J Clin Nutr 57:201-208

Bijlsma MJ, Hak E, Bos JH, de Jong-van den Berg LT, Janssen F (2012) Inclusion of the birth cohort dimension improved description and explanation of trends in statin use. J Clin Epidemiol 65:1052-1060

Camarda CG (2012) Mortality Smooth: an R package for smoothing Poisson counts with P-Splines. J Stat Softw 50:1-24

Clayton D, Schifflers E (1987a) Models for temporal variation in cancer rates. I: age-period and age-cohort models. Stat Med 6:449-467

Clayton D, Schifflers E (1987b) Models for temporal variation in cancer rates. II: age-period-cohort models. Stat Med 6:469-481

Dhillon PK, Yeole BB, Dikshit R, Kurkure AP, Bray F (2011) Trends in breast, ovarian and cervical cancer incidence in Mumbai, India over a 30-year period, 1976-2005: an age-period-cohort analysis. BJC 105:723-730

Diouf I, Charles MA, Ducimetiere P, Basdevant A, Eschwege E, Heude B (2010) Evolution of obesity prevalence in France: an age-period-cohort analysis. Epidemiology 21:360-365

Eurostat (2016) Census data. http://ec.europa.eu/eurostat. Accessed 19 August 2016

Eurostat (2017) Overweight and obesity-BMI statistics. http://ec. europa.eu/eurostat/statistics-explained/index.php/Overweight_ and_obesity_-_BMI_statistics. Accessed 15 July 2016 
Field AE, Coakley EH, Must A et al (2001) Impact of overweight on the risk of developing common chronic diseases during a 10-year period. Arch Intern Med 161:1581-1586

Finucane MM, Stevens GA, Cowan MJ et al, Global Burden of Metabolic Risk Factors of Chronic Diseases Collaborating Group (Body Mass Index) (2011) National, regional, and global trends in body-mass index since 1980: systematic analysis of health examination surveys and epidemiological studies with 960 country-years and 9.1 million participants. Lancet 377:557-567

Flegal KM, Graubard BI, Williamson DF (2004) Methods of calculating deaths attributable to obesity. Am J Epidemiol 160:331-338

Flegal KM, Graubard BI, Williamson DF, Gail MH (2005) Excess deaths associated with underweight, overweight, and obesity. JAMA 293:1861-1867

Flegal KM, Kit BK, Orpana H, Graubard BI (2013) Association of all-cause mortality with overweight and obesity using standard body mass index categories: a systematic review and metaanalysis. JAMA 309:71-82

Global BMI Mortality Collaboration (2016) Body-mass index and allcause mortality: individual-participant-data meta-analysis of 239 prospective studies in four continents. Lancet 388:776-786

Hellevik O (2002) Age differences in value orientation-life cycle or cohort effects? Int J Public Opin Res 14:286-302

Human Mortality Database (2016) University of California, Berkeley (USA), and Max Planck Institute for Demographic Research (Germany). http://www.mortality.org. Accessed 15 June 2016

Janssen F, Kunst AE (2005) Cohort patterns in mortality trends among the elderly in seven European countries, 1950-99. Int J Epidemiol 34:1149-1159

Janssen F, van Wissen LJ, Kunst AE (2013) Including the smoking epidemic in internationally coherent mortality projections. Demography 50:1341-1362

Jiang T, Gilthorpe MS, Shiely F et al (2013) Age-period-cohort analysis for trends in body mass index in Ireland. BMC Public Health 13:889

Johnson W, Li L, Kuh D, Hardy R (2015) How has the age-related process of overweight or obesity development changed over time? Co-ordinated analyses of individual participant data from five United Kingdom birth cohorts. PLoS Med 12:e1001828

Katzmarzyk PT, Ardern CI (2004) Overweight and obesity mortality trends in Canada, 1985-2000. Can J Public Health 95:16-20

Kelly C, Pashayan N, Munisamy S, Powles JW (2009) Mortality attributable to excess adiposity in England and Wales in 2003 and 2015: explorations with a spreadsheet implementation of the Comparative Risk Assessment methodology. Popul Health Metr $7: 11$

Lifestyles Statistics Team, Health and Social Care Information Centre (2014) Statistics on obesity, physical activity and diet: England
2014. http://content.digital.nhs.uk/catalogue/PUB13648/Obesphys-acti-diet-eng-2014-rep.pdf. Accessed 10 December 2016

Masters RK, Reither EN, Powers DA, Yang YC, Burger AE, Link BG (2013) The impact of obesity on US mortality levels: the importance of age and cohort factors in population estimates. Am J Public Health 103:1895-1901

Mehta NK, Chang VW (2009) Mortality attributable to obesity among middle-aged adults in the United States. Demography 46:851-872

Mehta T, Fontaine KR, Keith SW et al (2014) Obesity and mortality: are the risks declining? Evidence from multiple prospective studies in the United States. Obes Rev 15:619-629

$\mathrm{Ng} \mathrm{M}$, Fleming T, Robinson M et al (2014) Global, regional, and national prevalence of overweight and obesity in children and adults during 1980-2013: a systematic analysis for the Global Burden of Disease Study 2013. Lancet 384:766-781

OECD (2014) Obesity update. http://www.oecd.org/health/ObesityUpdate-2014.pdf. Accessed 3 November 2016

OECD (2016) OECD.Stat. http://stats.oecd.org/index.aspx?DataSet Code=HEALTH_STAT\#. Accessed 2 May 2016

Pico C, Palou M, Priego T, Sanchez J, Palou A (2012) Metabolic programming of obesity by energy restriction during the perinatal period: different outcomes depending on gender and period, type and severity of restriction. Front Physiol 3:436

Public Health England (2016) Adult obesity international comparisons data factsheet. http://www.noo.org.uk/NOO_pub/Key_ data. Accessed 28 October 2016

Reither EN, Hauser RM, Yang Y (2009) Do birth cohorts matter? Age-period-cohort analyses of the obesity epidemic in the United States. Soc Sci Med 69:1439-1448

Reither EN, Olshansky SJ, Yang Y (2011) New forecasting methodology indicates more disease and earlier mortality ahead for today's younger Americans. Health Aff 30:1562-1568

Rockhill B, Newman B, Weinberg C (1998) Use and misuse of population attributable fractions. Am J Public Health 88:15-19

Thun M, Peto R, Boreham J, Lopez AD (2012) Stages of the cigarette epidemic on entering its second century. Tob Control 21:96-101

Trias-Llimos S, Bijlsma MJ, Janssen F (2017) The role of birth cohorts in long-term trends in liver cirrhosis mortality across eight European countries. Addiction 112:250-258

WHO (1998) Obesity: preventing and managing the Global Epidemic: Report of a WHO Consultation on Obesity. World Health Organization, Geneva

Yu Y (2012) Reexamining the declining effect of age on mortality differentials associated with excess body mass: evidence of cohort distortions in the United States. Am J Public Health 102:915-922 